\title{
Mucocutaneous Adverse Drug Reactions In A Hospital Setting In Cameroon
}

\author{
J Mbuagbaw, L Egbembah Mbuagbaw, A Chiabi, C Bisseck, M Nkam
}

\begin{abstract}
Citation
J Mbuagbaw, L Egbembah Mbuagbaw, A Chiabi, C Bisseck, M Nkam. Mucocutaneous Adverse Drug Reactions In A Hospital Setting In Cameroon. The Internet Journal of Dermatology. 2007 Volume 6 Number 2.
\end{abstract}

DOI: $\underline{10.5580 / 2538}$

\begin{abstract}
Mucocutaneous drug reactions are common in our setting. Our objectives were to evaluate the prevalence of mucocutaneous drug reactions due to systemic drugs. A retrospective cohort study of outpatients with the diagnosis of Adverse Drug Reaction was carried out over 6 years in the University Teaching Hospital, Yaoundé.

138 cases of mucocutaneous drug reactions were evaluated. Fixed Drug Eruptions accounted for more than $60.7 \%$ of all the Adverse Drug Reactions. Sulphonamides were responsible for $82 \%$ of all the Fixed Drug Eruptions and were the offending drug in $65 \%$ of all the Adverse Drug Reactions documented. $28.9 \%$ of the subjects were HIV positive. 24 cases were hospitalized because of severity out of which 6 died (25\%). The prevalence of drug reactions in the study is $3.5 \%$. The most common drug reaction is the Fixed Drug Eruption. The most offending drugs are Sulphonamides.

Proper management of Adverse Drug Reactions is necessary and early referral of patients may be life saving.
\end{abstract}

\section{INTRODUCTION}

Drugs are used for the investigation, prevention or treatment of diseases. Adverse Drug Reactions (ADRs) occur mostly on the skin and mucus membranes. The incidence of mucocutaneous drug reactions varies form 6-15\% $\left(_{1}\right)$ and has been reported to be as high as $30 \%\left({ }_{2}\right)$ in some centers. One in forty consultations is due to adverse drug reactions $\left.{ }_{3}\right)$. Surveys in the United Kingdom revealed that not more then $10 \%$ of adverse drug reactions are reported $\left({ }_{4},{ }_{5}\right)$.

In Cameroon, no study has been done on the prevalence of drug reactions. The types of reactions will vary depending on which drugs are most frequently used and on which pathologies are most common. Sulphonamides are used a lot in sub-Saharan Africa for the treatment of malaria and HIV opportunistic infections.

\section{OBJECTIVES}

The objective of the study was to evaluate the clinical spectrum and demography of Adverse Drug Reactions in the Dermatology clinic of the University Teaching Hospital in Yaoundé and to describe the risk factors associated.

We also aimed at documenting the causal link between drugs and reactions using the WHO definition of causality for future health planning and case management.

\section{MATERIAL AND METHODS}

A retrospective descriptive study of all patients diagnosed with mucocutaneous Adverse Drug Reactions (ADRs) was carried out covering a period of six years from January 2000 to January 2006, in the Dermatology clinic of the University Teaching Hospital, Yaoundé, Cameroon.

\section{RESULTS}

A total of 138 cases of mucocutaneous ADRs to systemic drugs were evaluated. There were two groups of patients; those with certain or probable causal relationships with the reactions ( $\mathrm{n}=129)$, and those in whom no drug causal relationship was found $(n=9)$. The ages ranged form 1 to 70 years. There were 56 males $(40 \%)$ and 82 females $(60 \%)$. The prevalence of ADRs was 3.5\%. Fixed Drug Eruption (FDE) accounted for more than half of the ADRs (60.7\%). Sulphonamides, either singly or in combination with Pyrimethamine or Trimethoprime were responsible for $82 \%$ of all the FDE and the offending drug in $65 \%$ of cases (90/138). Sulphonamides were also incriminated in Lyell's syndrome (72\%), Steven Johnson Syndrome (60\%) and Erythema Multiforme (75\%). The other offending drugs were in order of decreasing frequency; Nevirapine $(8.7 \%)$, 
Penicillins (4.3\%), Anticonvulsants (3.6\%), Paracetamol (2.9\%), Griseofulvine (1.4\%) and Doxicycline (1.4\%). See Table 1.
$28.9 \%$ of the subjects were HIV positive (40/138). 24/ 138 were admitted for management of severe lesions. 6 died from Lyell's syndrome (Toxic Epidermal Necrolysis). 


\section{Figure 1}

Table 1: Morphology (type) of eruption and the causative drugs.

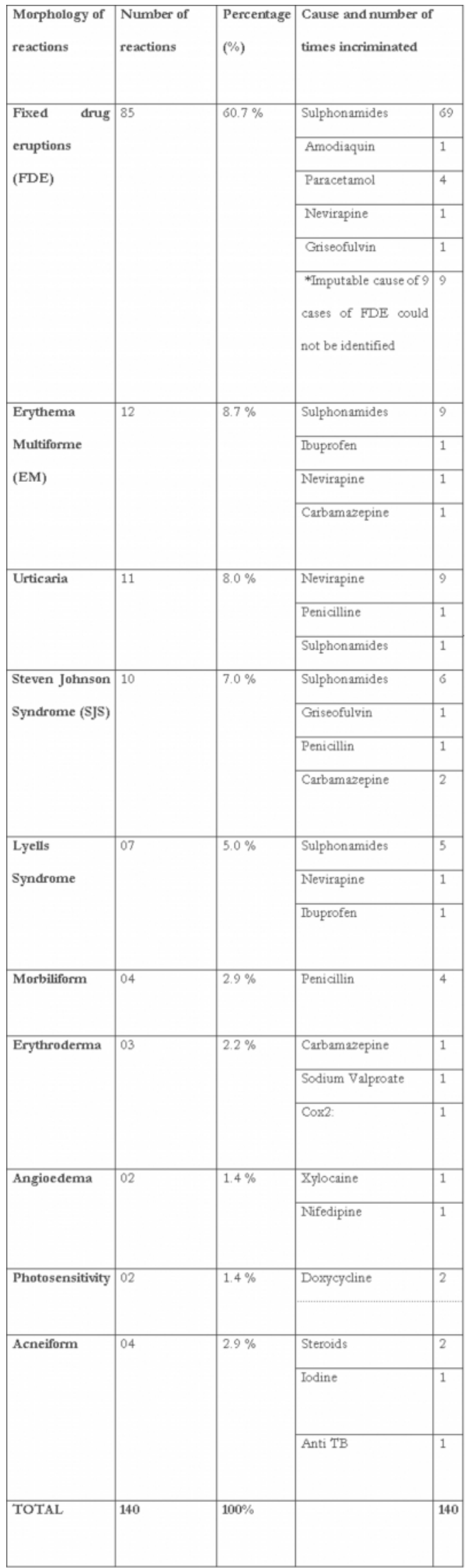

NB: Some patients had more than one ADR 


\section{DISCUSSION}

The exact prevalence of ADRs may be difficult to obtain owing to the fact that the investigator must rely on the patient reporting accurately, on the kind of drug taken. Because the skin has limited number of morphological reactions to drugs, it may be sometimes more difficult to determine the offending drug.

We found a prevalence of $3.5 \%$. Other studies have reported $11.6 \%$ and $0.7 \%\left({ }_{6},{ }_{7}\right)$. Our findings on FDE are similar to those of Nnoruka et al $\left.{ }_{8}\right)$ in Nigeria who reported FDEs as the most common ADRs. The prevalence of FDEs varies widely from country to country with values ranging from 12 $27 \%\left({ }_{8}, 9,10\right)$.

On the contrary, studies in western countries have morbiliforme eruptions as the most frequent ADRs. In these countries aminopenicillins are incriminated and are the most commonly used drugs. $\left(6,{ }_{11},{ }_{12}\right)$

Many studies have confirmed the increased incidence of ADR among HIV infected patients as compared to the general population $\left({ }_{13},{ }_{14},{ }_{15}\right)$. This can be explained by the increased number of drugs prescribed for these patients and the higher risk of drug interaction and possible immune dysregulation $\left({ }_{15}\right)$. One of the HIV positive cases had severe Steven Johnson Syndrome(SJS). Nevirapine has been reported to cause SJS $\left({ }_{16},{ }_{17}\right)$. Drug reaction in HIV patients may be as high as $50 \%$.

Only $17.4 \%(24 / 138)$ of our patients had severe reactions as compared to $34 \%$ in a French study. $\left({ }_{18}\right)$

\section{CONCLUSION}

Automedication, poor reporting of ADRs and alternate forms of medicine may prevent proper recording of drug reactions in a community. The prevalence of ADRS is comparable with literature. Survival rates from severe reactions can be improved if adapted centers were available.

We recommend that, patients should carry drug cards indicating which drugs they are allergic to. Attending physicians should always ask of any drug allergies. Owing to the therapeutic implications and constraints of ADRs, review by a Dermatologist may be necessary. A multidisciplinary approach is encouraged. Referral to a well equipped burn center may be life saving.

\section{References}

1. De Swarte R.D.

Drug allergy problems and strategies.
J Allergy Clin Immunol. 1984:74, 209-21.

2. Jick $\mathrm{H}$.

Adverse drug reactions: The magnitude of the problem.

J Allergy Clin Immunol. 1984:74, 555-7.

3. Matys C. R.

Adverse reactions to drugs in general practice.

Br Med J.1979: ii: 1194-7.

4. Nolan L, O'Malley K.

Adverse drug reactions in the elderly.

Br J Hosp Med. 1989: 41: 446-57.

5. Rawlins M. D., Breck A. M., Wood S M.

National adverse drug reactions reporting a silver jubilee.

Adverse drug React Bill. 1989: 138: 516 - 19.

6. María del Mar Campos-Fernández, Samuel Ponce-de-

León-Rosales, Carla Archer-Dubon,Orozco-Topete R.

Risk factors for cutaneous adverse drug reactions in an intensive care unit.

Rev Invest Clin 2005; 57 (6): 770-774

7. Hernandez-Salazar A, de Leon-Rosales S P, Rangel-

Frausto S, Criollo E, Archer- Dulbon C, Orozco- Topete R. Epidemiology of adverse drug reactions in. A prospective study in hospitalized patients.

Archives of Medical Research. 2006: Volume 37, Issue 7,

Pages 899-902

8. Edith N Nnoruka, V O Ikeh, A U Mbah.

Fixed drug eruptions in Nigeria.

International J dermatol.2006: 1062- 1065.

9. Than S N, Kwok Y K, Chan H L.

Cross reactivity in fixed drug eruptions to tetracycline.

Arch Dermatol. 1996: 132: 1134 - 1135.

10. Thankappan T P, Zechariah J.

Drug specific clinical pattern in fixed eruptions.

Int J Dermatol.1990: 30: 867-870.

11. Eichmann A

Skin manifestations in patients with HIV infections.

Z Hauter. 1990: 65(7): 640-4.

12. Hunziker T, Kunzi U P, Braunschweig S, Zehnder D, Hoigne R

Comprehensive hospital drug monitoring (CHDM): adverse skin reactions; a 20 year survey.

Allergy. 1997: 52(4):388

13. Rademaker M, Oakley A, Duffill M B.

Cutaneous adverse reactions in a hospital setting.

NZ Med J.1995: 108(999):165 - 6

14. Coopman S A, Johnson R A, Plett R et al.

Cutaneous disease and drug reactions in HIV infection.

N Engl. J Med. 1993: 328: 1670-1674.

15. Smith K J, Skelton H G, Yeagor J, Ledsky R, Ng T H, wagner K F.

Military Medical Consortium for the Advancement of

Rational Research (MMCARR). Increased drug reactions in

HIV-1- positive patients: a possible explanation based on patterns of immune dysregulation seen in HIV-1 disease.

Clin Exp Dermatol.1997: 22: 118-123.

16. Metry D W, Lahart C J, Farmer K L et al.

Stevens Johnson Syndrome caused by the antiretroviral drug nevirapine.

J Am Acad dematol.2001: 44: 354-357.

17. Munoz-Perez M.A, Rodriguez-pechardo A, Camacho F, Colmenero M. A.

Dermatological findings correlated with CD4 lymphocyte counts in a prospective 3 -year study on 1161 patients with human immunodeficiency virus disease predominantly acquired through intravenous drug abuse.

Br J Dermatol.1998: 139(1) 33 - 9

18. Fizzonson-Albalaf, Auzene V, Mahe E et al

A 6-month prospective survey of cutaneous drug reactions in a hospital setting. 
Br J Dermatol. 2003 Nov: 149(5): 1018-22. 


\section{Author Information}

\section{Josephine Mbuagbaw}

Internal Physician and Dermatologist, Department of Medicine and Specialties, FMBS, University of Yaoundé I

\section{Lawrence Chinedu Egbembah Mbuagbaw}

Medical Doctor, Bafut District Hospital, Bafut Health District

\section{Andreas Chiabi}

Paediatrician, Department of Pediatrics, Faculty of Medicine and Biomedical Sciences

\section{Cecile Bisseck}

Dermatologist, Dermatology sub unit, Department of Medicine, Faculty of Medicine and Biomedical Sciences, University of Yaoundé I

\section{Maurice Nkam}

Anesthesiologist, Intensive Care Unit, University Teaching Hospital Yaoundé (CHUY) 